\title{
Fostamatinib for persistent/chronic adult immune thrombocytopenia
}

\author{
Adrian Newland ${ }^{*}, 1$, Eun-Ju Lee ${ }^{2}$, Vickie McDonald ${ }^{3}$ \& James B Busse ${ }^{4}$ \\ ${ }^{1}$ Academic Haematology Unit, Blizard Institute, Barts \& The London School of Medicine \& Dentistry, Queen Mary University of \\ London, London, UK \\ ${ }^{2}$ Division of Hematology/Oncology, Department of Medicine, Weill Cornell Medicine, New York, NY, USA \\ ${ }^{3}$ Department of Haematology, The Royal London Hospital, Barts Health NHS Trust, London, UK \\ ${ }^{4}$ Division of Pediatric Hematology/Oncology, Department of Pediatrics, Weill Cornell Medicine, New York, NY, USA \\ * Author for correspondence: Tel.: +44 (0) 203246 0338; Mob.: +44 (0) 7768 130865; Fax: +44 (0) 2032460351 ; \\ a.c.newland@qmul.ac.uk
}

Immune thrombocytopenia (ITP) is an acquired autoimmune disorder characterized by phagocytosis and destruction of autoantibody-coated platelets via spleen tyrosine kinase (Syk)-mediated signal transduction in macrophages. Effectiveness of existing therapies varies, and even leading treatments (e.g., IVIg, splenectomy, rituximab, thrombopoietic agents) do not provide optimal management for a substantial number of patients with chronic ITP. Fostamatinib disodium is an orally-bioavailable investigational agent being developed for treatment of primary persistent/chronic adult ITP. Fostamatinib inhibits FcR-triggered, Sykdependent cytoskeletal rearrangement during phagocytosis. Promising findings have been described in several autoimmune diseases, including rheumatoid arthritis, and sustained responses with manageable adverse events observed with ongoing treatment in patients with heavily treated chronic ITP. Fostamatinib represents an active therapy targeting a previously unexplored mechanism of ITP pathogenesis.

First draft submitted: 20 July 2017; Accepted for publication: 30 August 2017; Published online: 2 October 2017

Keywords: autoimmune $\bullet$ FcR $\bullet$ fostamatinib $\bullet$ immune thrombocytopenia $\bullet$ phagocytosis $\bullet$ signal transduction $\bullet$ spleen tyrosine kinase $\bullet$ Syk $\bullet$ targeted therapy $\bullet$ tyrosine kinase inhibitors

Primary immune thrombocytopenia (ITP) is an acquired autoimmune bleeding disorder characterized by a low platelet count $(<100,000 / \mu \mathrm{l})$ in the absence of other causes or disorders associated with thrombocytopenia [1]. The combined effects of platelet destruction and impaired platelet production often leads to severe thrombocytopenia with skin and mucosal bleeding and risk of serious intracranial and gastrointestinal bleeding complications [2-4]. Prevalence of ITP is estimated at 9.5 per 100,000 adults, and incidence rates have been reported at 3.3 adults per 100,000 years [5]. In adults, the prevalence of ITP increases with age [6]. Some reports have suggested that incidence is slightly higher in women of reproductive age and the elderly [4,5].

Adult ITP is a heterogeneous disease that can persist for years, even with best available care, and treatments are infrequently curative [4]. Despite availability of several treatments with differing mechanisms of action, chronicity of disease continues to be a problem. A significant proportion of patients develop resistance to treatment and thereby are prone to relapse [7]. The inflammatory biology and relapse/refractory nature of ITP pose both physical and psychosocial challenges to patients who have to live with the disease for prolonged periods.

The spleen tyrosine kinase (Syk) signaling pathway has emerged as a potential new target for treatment of autoimmune diseases, such as ITP. As platelet destruction in ITP is mediated by Syk-dependent phagocytosis of $\mathrm{Fc}_{\mathrm{C}} \mathrm{R}$-bound platelets [8], Syk inhibition represents a promising approach to management of ITP. Here, we review the current understanding of Syk in human biology, including the role of Syk in ITP, with a focus on fostamatinib, an investigational Syk inhibitor in clinical development for the treatment of persistent and chronic ITP in adults.

Future Medicine 


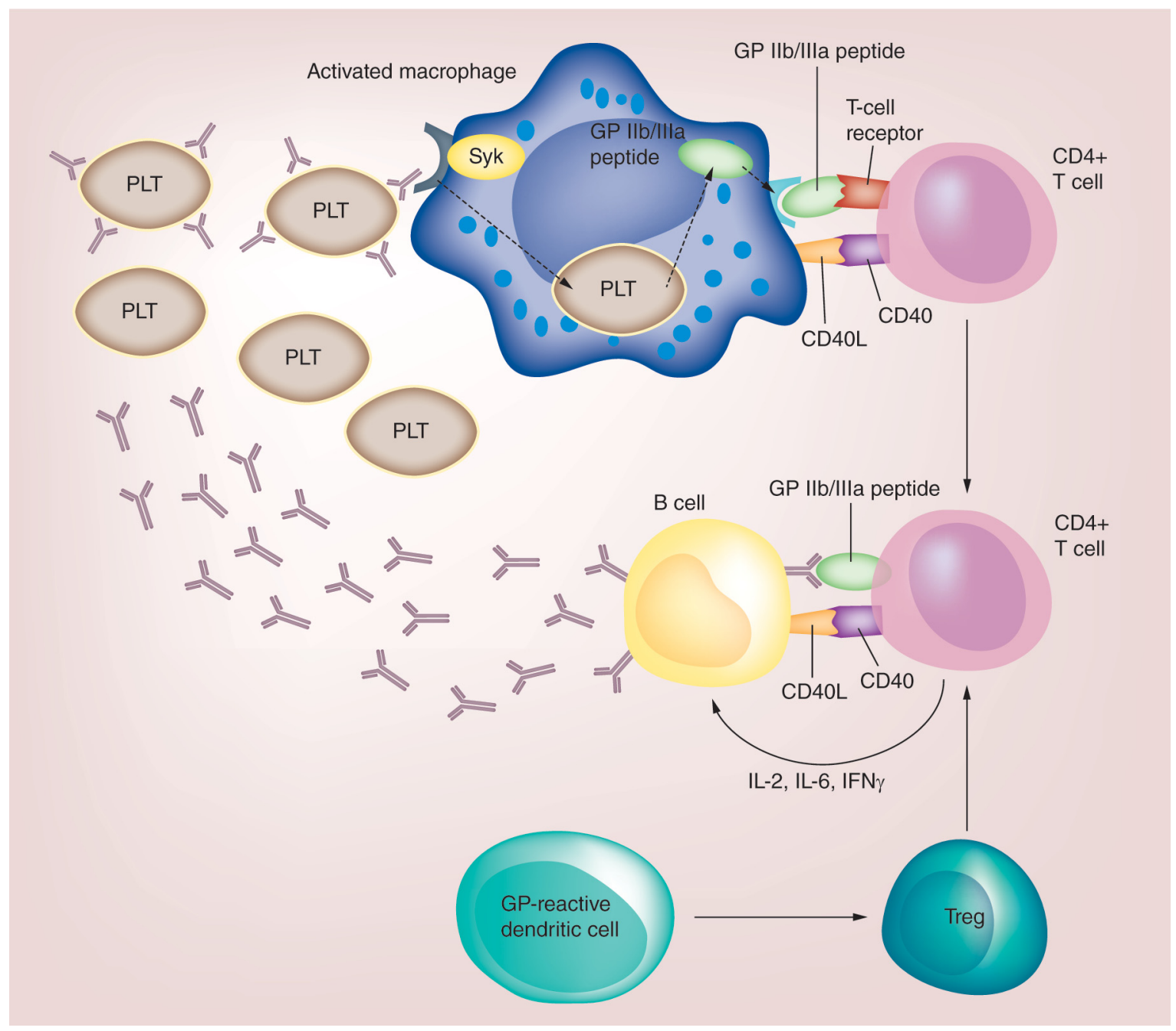

Figure 1. Pathogenesis of immune thrombocytopenia.

ITP is an autoimmune disease caused by antiglycoprotein autoantibodies that deplete platelets via destruction and inhibition of megakaryocyte production of new platelets. Autoantibodies-coated platelets and bind to antigen-presenting cells through the FcR, leading to Syk-dependent platelet engulfment and destruction by macrophages. Activated macrophages and dendritic cells induce proliferation of platelet-reactive CD4 ${ }^{+}$Th cells and Treg cells, which together amplify the production of antiplatelet antibodies from activated B cells. GP: Glycoprotein; ITP: Immune thrombocytopenia; PLT: Platelet.

\section{Pathogenesis of ITP}

ITP results from autoantibody- and T-cell-mediated platelet destruction and impaired platelet production. The best demonstrated targets of the autoimmune response in ITP are certain glycoproteins (GP) on the surface of platelets (Figure 1) [9]. Primary ITP has no known underlying causes; in contrast secondary ITP, by definition, has a number of clear precipitating factors, such as lymphoproliferative disease, common variable immunodeficiency, chronic viral and bacterial infections (i.e., hepatitis C, human immune deficiency virus, cytomegalovirus and Helicobacter pylori), and many drugs, including quinine or quinidine, heparin, penicillin, nonsteroidal anti-inflammatory drugs, anticonvulsants, antirheumatic and oral antidiabetic agents. There is also a strong association with other autoimmune disorders such as systemic lupus erythematosus and Hashimoto's thyroiditis $[1,10]$. When a patient with ITP presents, it is often not initially apparent whether it is primary or secondary.

ITP is a heterogeneous autoimmune disorder with diverse mechanisms of pathogenesis and variability in clinical features. The disease is believed to develop as a consequence of defects in immune tolerance. Perturbation of B-and T-cell tolerance can result in clonal expansion of platelet-reactive antibodies that arise through somatic mutations. 
These tolerance defects can occur centrally, during differentiation, or peripherally. The latter is thought to result in a platelet-specific disorder (primary ITP) that is more sensitive to therapy and less prone to relapse [11].

Most patients with primary ITP have a skewed Th1/Th2 ratio with increased levels of IFN- $\gamma$, IL-2 and IL-17, and decreased peripheral Th2 and Treg cells [12-14]. This shift appears to favor the survival of autoreactive T-cell clones and drive T-cell-dependent, antigen-driven clonal expansion and somatic mutations of autoantibodies in ITP [15]. Platelet and/or megakaryocyte lysis can also occur via cytotoxic $\mathrm{CD} 8^{+} \mathrm{T}$ cells expression of granzymes, Apo1/Fas, and perforin [16]. Autoantibodies initially target platelet surface glycoproteins, primarily GPIIbIIIa (integrin $\alpha \mathrm{IIb} \beta 3$ ) and GPIb/IX [17,18], but epitope spreading enables the production of antibodies against additional targets [19]. Upon the binding of autoantibodies, platelets are cleared by splenic macrophages through Fc $\gamma \mathrm{R}-$ mediated phagocytosis, although alternative mechanisms for platelet clearance, such as complement-dependent lysis, have been described $[9,20]$. In addition, abnormalities in megakaryocyte proliferation and differentiation attributed to the presence of autoantibodies diminish platelet production [21-23]. Interestingly, antiplatelet antibodies are only detectable in $60 \%$ of patients, and presence of these antibodies are not always associated with active disease [20,24], suggesting antibody-independent mechanisms, for example, cytotoxic $\mathrm{T}$ cells, may be responsible for thrombocytopenia in some patients [4].

\section{Unmet medical need}

Patients with ITP exhibit symptoms of petechiae, purpura, and gastrointestinal and/or urinary mucosal tract bleeding [2]. The greatest concern with ITP is the risk of significant bleeding, such as intracranial hemorrhage; the 5 -year fatal hemorrhage rate is higher in older patients with ITP, especially in those with comorbid conditions [24]. Other clinically significant concerns include complications from internal bleeding and elevated risk of arterial thrombosis and venous thromboembolism [25]. In addition to physical bleeding-related manifestations of the disease, ITP has been associated with fatigue (reported in up to $39 \%$ of adults with ITP [4]]), as well as impaired quality of life across domains of emotional, functional and reproductive health, and work and social life. These symptoms that accompany the disease interfere with daily activities and can lead to feelings of embarrassment, isolation and sexual inadequacy [26-30].

ITP is classified into three distinct phases of disease: newly diagnosed (within 3 months of diagnosis); persistent (between 3-12 months from diagnosis); and chronic (lasting for more than 12 months) [1]. According to the ITP International Working Group, the goal of therapy for ITP is to provide a safe platelet count - one that prevents major bleeding, rather than correcting platelet count to normal levels. However, for patients with persistent/chronic ITP, treatment selection is not well defined, as management decisions are often driven not only by platelet guidelines, but also by avoidance of toxicities from treatments. For example, minimizing corticosteroid exposure has been described as a key principle in managing chronic ITP [1].

Perhaps, the greatest challenge with managing persistent/chronic ITP in adults is the likelihood of relapse or refractoriness to treatment [31]. No 100\% cure exists, and the effectiveness of existing therapies are variable and unpredictable [32]. Although multiple options now exist for patients with relapsed and refractory disease, particularly with the development of thrombopoietin receptor agonists (TPO-RA), none reliably induce durable remission except for splenectomy and rituximab-based therapy in certain cases [4]. Thus, there is a need for additional therapeutic options that target previously unexplored disease mechanisms in ITP.

\section{Current management of ITP}

Current therapeutic approaches for treatment of ITP have been developed to target distinct events that occur along the pathogenesis pathway, either through inhibition of immunological events that promote destruction or inhibit development of platelets (e.g., steroids, intravenous immunoglobulin (IVIg), anti-D, rituximab) or by promoting the production of new platelets (i.e., TPO-RA; Figure 2).

Current guidelines established by the American Society of Hematology and the International Consensus Report recommend use of steroids (with or without IVIg or anti-D, as clinically indicated) for first-line therapy [7,33]. For second- or later lines, American Society of Hematology recommends splenectomy, followed by TPO-RAs or rituximab in patients who are at risk of bleeding or fail splenectomy [33], whereas the International Consensus Report lists splenectomy, TPO-RA, rituximab, immunosuppressive agents, danazol/dapsone and cyclosporin A, among a longer list of recommended therapies, but in no preferential order in view of the lack of an evidence base to favor one treatment over another [7]. 


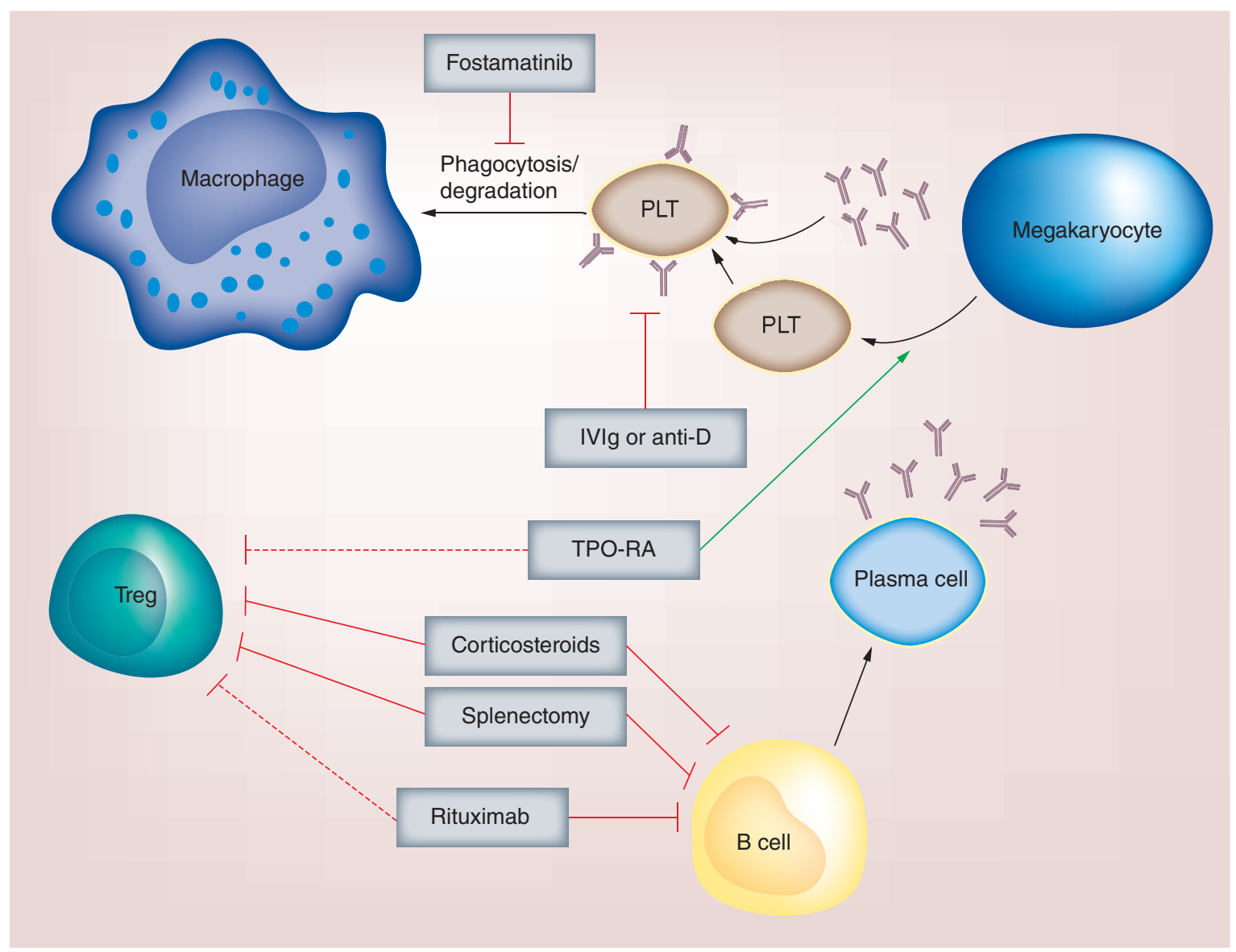

Figure 2. Treatments for immune thrombocytopenia: mechanisms of action.

Treatments for chronic ITP consist of agents that inhibit various components of the immune system or stimulate production of new platelets. First-line treatments consist of corticosteroids, which function to inhibit Treg and B-cell function and modulate FcR function, with or without IVIg and anti-D, which impair antigen presentation and competitively inhibit macrophage recognition of autoantibody-coated platelets. Second-line options include surgical approaches, such as splenectomy, which physically removes the primary site of platelet destruction, and medical approaches, including rituximab, which directly targets and depletes antibody-producing B cells, and TPO-RAs, such as romiplostim and eltrombopag, that stimulate megakaryocyte production of new platelets. Fostamatinib is a new investigational agent that impairs phagocytosis of platelets via inhibition of Syk. Red lines indicate inhibitory effects; green arrows indicate stimulatory effects.

ITP: Immune thrombocytopenia; IVIg: Intravenous immunoglobulin; PLT: Platelet; TPO-RA: Thrombopoetin receptor agonist.

Agents currently under investigation for the treatment of ITP include, but are not limited to Syk inhibitors, monoclonal antibodies against CD40L or CD20, nonspecific immunosuppressants, platelet-increasing therapies (e.g., new TPO-RAs), FcRn blockers, and inhibition of B lymphocyte stimulators [32].

Despite the availability of therapies that are initially effective for many patients, there remains a significant population of patients with relapsed or refractory disease who have limited sensitivity to currently available agents and are in need of a new approach to treatment. With a steadily growing number of therapies targeted against various components of the ITP pathogenesis pathway, the Syk kinase pathway represents a new target that has previously shown promising results in other models of autoimmune disease. This review focuses on the value of Syk as a new target for inhibition by fostamatinib in the treatment of ITP.

\section{Fostamatinib disodium}

Fostamatinib disodium (R935788, R788) is an investigational agent in clinical development for the treatment of primary persistent/chronic adult ITP [34]. It is a relatively selective Syk inhibitor that reduces platelet destruction in patients with ITP by inhibiting Fc $\gamma$ R-mediated signal transduction and preventing cytoskeletal rearrangement 


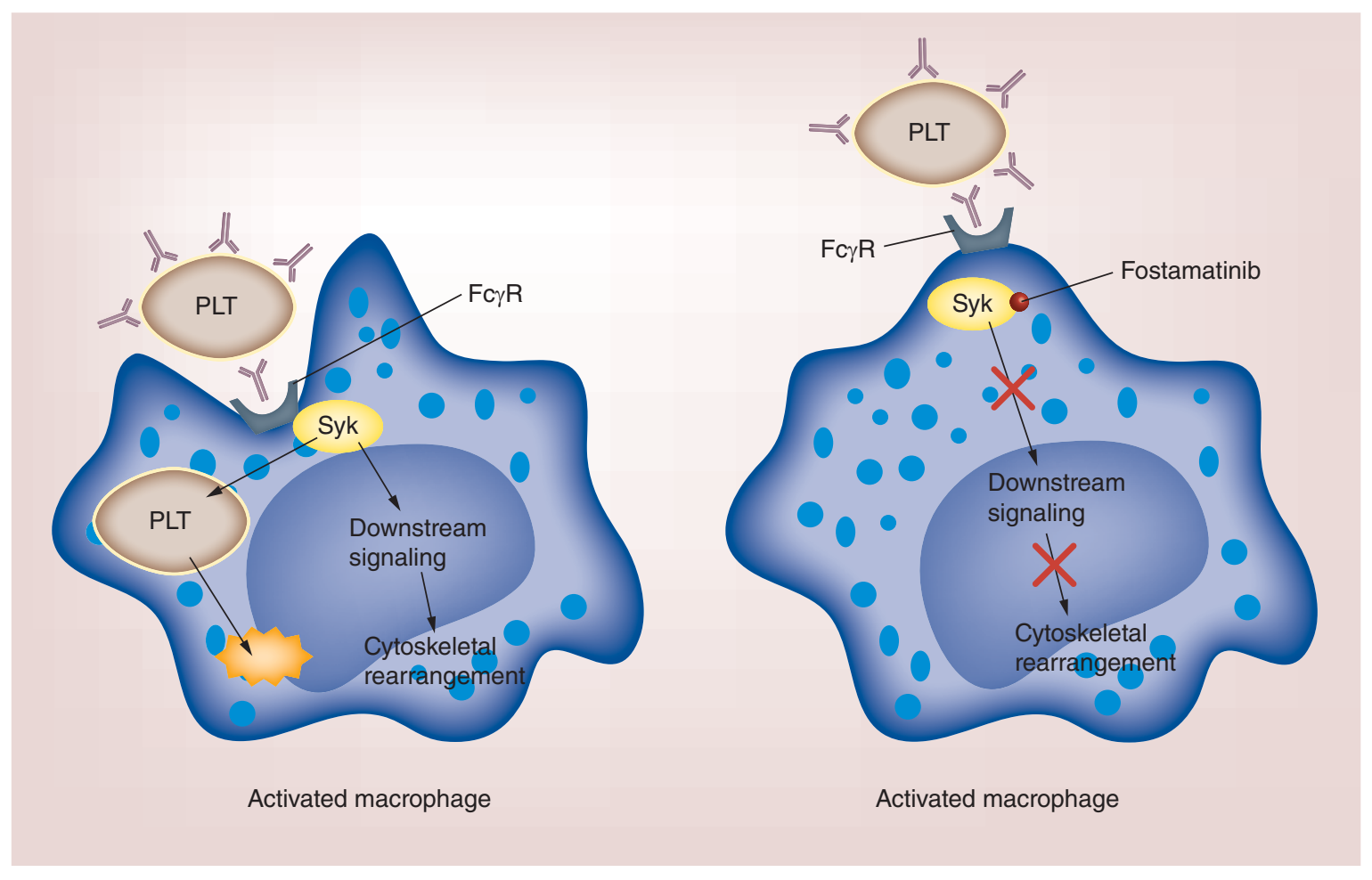

Figure 3. Proposed mechanism of action of fostamatinib in immune thrombocytopenia.

Fostamatinib is an inhibitor of Syk, a tyrosine kinase involved in the FCR signaling pathway. Upon binding of FCR to their ligands, receptor ligation results in phosphorylation ITAMs by SRC family tyrosine kinases (or by Syk itself), followed by recruitment and downstream signaling from Syk that result in cytoskeletal rearrangement and phagocytosis. Inhibition of Syk by fostamatinib and its active metabolite R406 is believed to impair Syk-dependent phagocytosis of autoantibody-coated platelets. Left panel shows normal phagocytosis by macrophages; right panel shows inhibition of phagocytosis by fostamatinib.

ITAMs: Immunoreceptor tyrosine-based activation motif.

needed for phagocytosis of autoantibody-coated platelets by macrophages (Figure 3). It is a 732.5 MW disodium hexahydrate that offers broad potential for use in several Syk-dependent indications, including autoimmune and inflammatory diseases. It has been studied in preclinical models of chronic lymphocytic leukemia, systemic lupus erythromatosus, glomerulonephritis, ischemia and diabetes. Clinical studies have been conducted in patients with IgA nephropathy, B-cell and T-cell lymphoma, solid tumors, systemic lupus erythromatosus, rheumatoid arthritis, autoimmune hemolytic anemia (AIHA) and ITP. While there are a number of other Syk inhibitors currently in development (e.g., entospletinib, RO9021, GSK 2646264, GS-9973), only fostamatinib has been studied in patients with ITP to date.

\section{Spleen tyrosine kinase inhibition}

Syk is a key regulator in signal transduction pathways involved in development and progression of autoimmune diseases, such as rheumatoid arthritis and ITP [35-38]. It is a member of the cytoplasmic protein tyrosine kinase family that is expressed extensively in hematopoietic cells, including macrophages, B cells, $\mathrm{T}$ cells, dendritic cells and platelets [39]. Syk is recruited and activated upon binding of $\mathrm{Fc} \gamma \mathrm{Rs}$ to their ligands. Receptor ligation leads to phosphorylation of immunoreceptor tyrosine-based activation motifs by SRC family tyrosine kinases (or by Syk itself), which leads to recruitment of Syk and activation of downstream signaling cascades that in turn lead to such responses as proinflammatory responses or cytoskeletal rearrangement and phagocytosis (Figure 4) [8,39,40].

Macrophages derived from Syk knockout mice are defective in phagocytosis of Fc $\gamma \mathrm{R}$-bound particles and in Fc $\gamma$ R-induced signaling events [8]. Inhibition of Syk is protective against development of thrombocytopenia and anemia in murine models of ITP and AIHA, respectively, and against inflammation in models of rheumatoid arthritis [36-38,41-45]. 


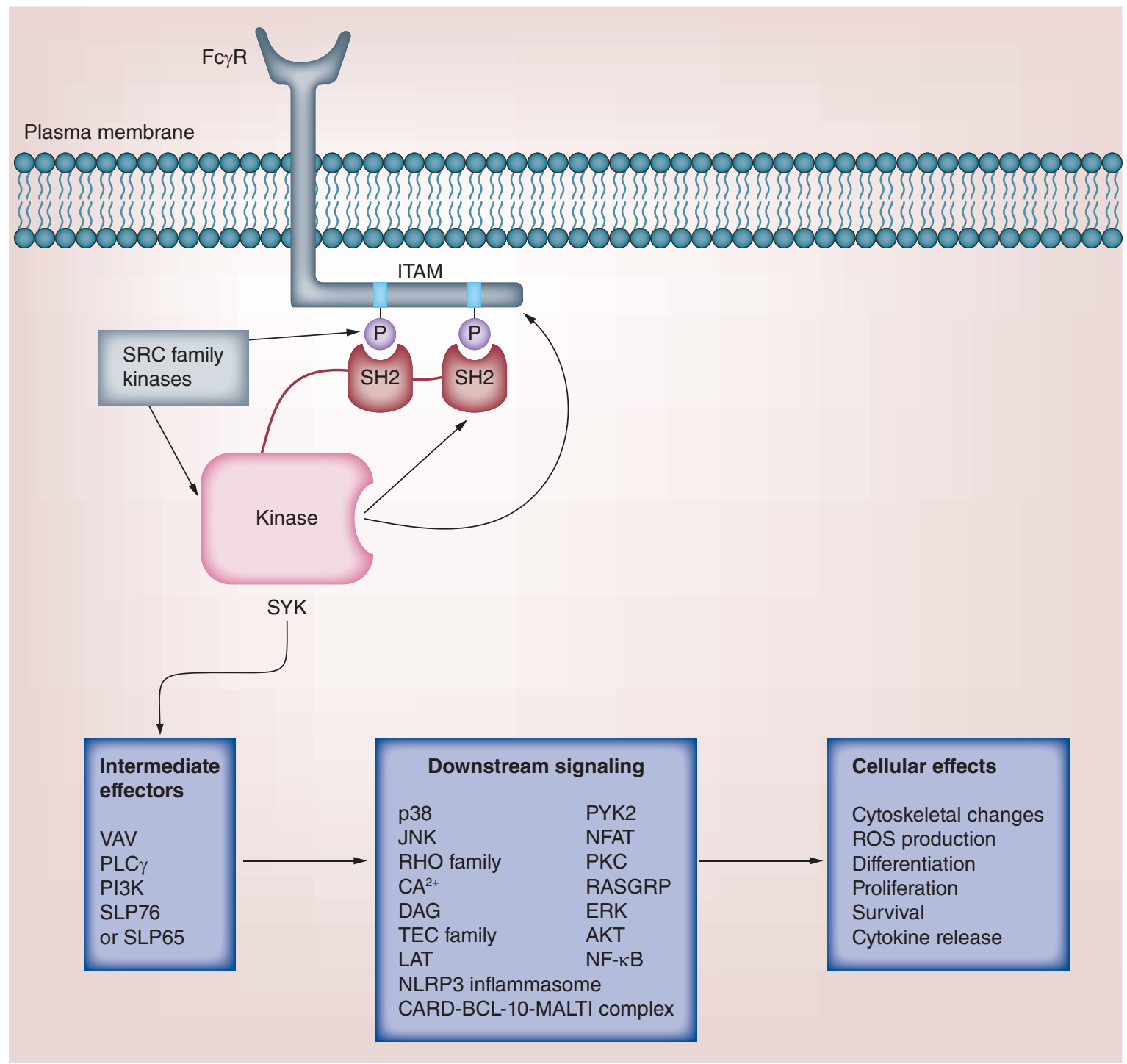

Figure 4. Fc $\gamma$ R-Syk signaling pathways.

Syk is recruited to the cytoplasmic tail of the Fc $\gamma \mathrm{R}$ via binding of tandem $\mathrm{SH} 2$ domains to phosphotyrosine residues of the receptor ITAM motif. Subsequent activation of Syk leads to direct binding to signaling intermediates, VAV, PLC $\gamma$, PI3K or SLP76/SLP65, which then triggers the activation of downstream signaling cascades, resulting in several types of cellular responses, including cytoskeletal rearrangement and phagocytosis.

ITAM: Immunoreceptor tyrosine-based activation motif; ROS: Reactive oxygen species.

\section{Pharmacology}

Fostamatinib (N4-(2,2-dimethyl-4-[(dihydrogenphosphonoxy)methyl]-3-oxo-5-pyrid[1,4] oxazin-6-yl)-5-fluoroN2-(3,4,5-trimethyoxy-phenyl)-2,4-pyrimidinediamine disodium hexahydrate) is an orally bioavailable prodrug that is metabolized into a biologically active form, R406 (N4-2,2-dimethyl-3-oxo-4H-pyrid[1,4] oxazin-6-yl)5-fluoro-N2-(3,4,5-trimethoxyphenyl)-2,4-pyrimidinediamine), a selective small molecule inhibitor of Syk (Figure 5) [31,46].

$\mathrm{R} 406$ was initially identified as a relatively specific inhibitor of $\mathrm{F} \in \mathrm{R}$-dependent mast cell activation in a cell-based screen for structure activity relationships with primary human mast cells [37]. However, due to the low aqueous solubility of R 406, fostamatinib was designed as a methylene-phosphate prodrug that is cleaved to the biologically active R 406 by alkaline phosphatases at the apical brush-border membranes of intestinal enterocytes [31,46]. R406 is a potent and selective inhibitor of Syk; it inhibits Syk kinase activity by binding the catalytic domain $\left(\mathrm{K}_{\mathrm{i}}=30 \mathrm{nM}\right)$ and acts as an ATP-competitive inhibitor $\left(\mathrm{IC}_{50}=41 \mathrm{nM}\right)$ [37]. 


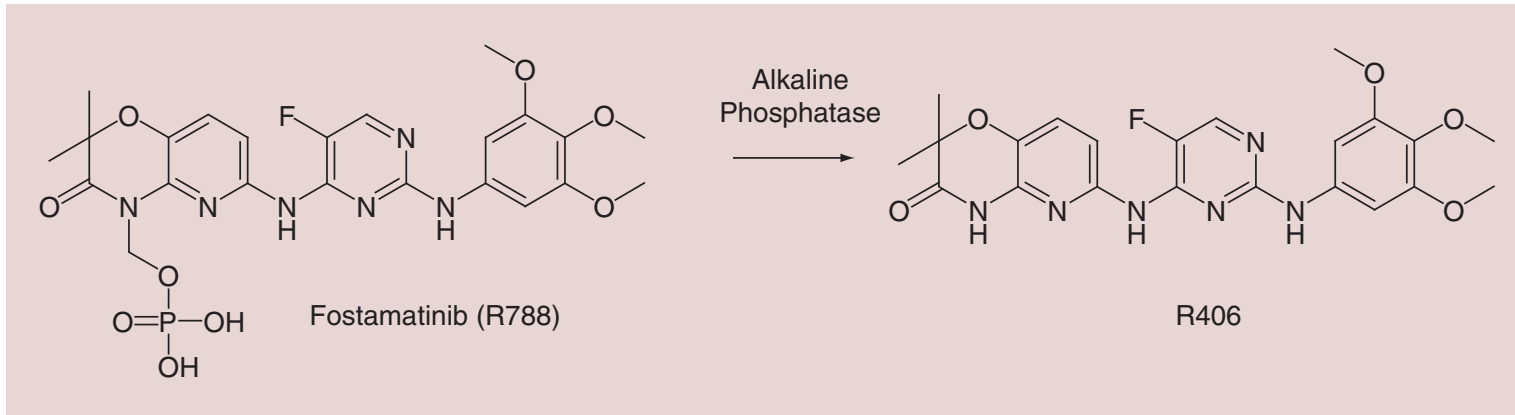

Figure 5. Metabolism of orally bioavailable prodrug, fostamatinib, to biologically active form, R406. via alkaline phosphatases at the apical brush-border membranes of intestinal enterocytes.

As with other kinase inhibitors, additional molecular targets of fostamatinib have been explored to investigate potential off-target effects that may contribute to its pharmacological effects [47,48]. Selectivity of R 406 has been demonstrated in panels of in vitro and cell-based assays. In an initial selectivity assessment of 90 in vitro kinase assays, R406 bound to other targets (i.e., Flt3, Lyn and Lck), but showed five- to 100-fold greater inhibition of Syk than other tyrosine kinases when tested in a phosphorylation assay [37,49]. More recently, Rolf et al. presented a comprehensive pharmacological profile of fostamatinib/R406, using a broad range of in vitro assays, followed by functional and cellular assays to further understand the relevance of key targets at therapeutically relevant concentrations [48]. Among nonkinases, antagonist activity was found against adenosine $\mathrm{A}_{3}$ receptor, inhibiting adenosine uptake with an $\mathrm{IC}_{50}$ of $100 \mathrm{nmol} / \mathrm{l}$. In a kinase screen of 387 individual kinases, R406 bound and showed activity against 117 kinases, 100 of which had $\mathrm{IC}_{50}$ within three-fold of Syk. Out of these, the authors noted prior association of FLT1, KDR, SRC and KIT with blood pressure, based on their analysis of published literature [48].

In a separate kinase screen, VEGFR2 was identified as a secondary target of fostamatinib and further evaluated as a possible mechanism for the elevated blood pressure and increased incidence of hypertension previously observed in clinical studies of fostamatinib $[47,50]$. Off-target inhibition of VEGFR2 was found to increase vascular resistance and reduced VEGF-induced nitric oxide release in animal models [50], where effects were dose-dependent, but effectively managed by drug withdrawal or concomitant treatment with antihypertensive agents [51]. R406 also inhibited VEGF-dependent human endothelial cell tube formation and tube outgrowth, further supporting a possible role for VEGF signaling in blood pressure effects of fostamatinib [48].

\section{Pharmacodynamics}

Through inhibition of Syk, fostamatinib elicits immunomodulatory effects via inhibition of FcR and B-cell receptor signaling. These effects have been explored in autoimmune and inflammatory disease models, as well as in models of hematologic malignancies (i.e., B-cell lymphomas and chronic lymphocytic leukemia), in which fostamatinib/R406 has shown inhibition or delayed onset of disease progression [36-38,41-45,52,53].

In in vitro studies, R406 inhibited Syk-mediated IgE- and IgG-mediated activation of FcR signaling and FC $\in \mathrm{R}$ - and FC $\gamma \mathrm{R}$-dependent responses in a number of cell types [37,54]. R406 inhibited degranulation, cytokine production and FcR-mediated antigen internalization in mast cells, tumor necrosis factor- $\alpha$ (TNF- $\alpha$ ) production induced by Fc $\gamma \mathrm{R}$-cross-linking in macrophages, anti-IgG-induced oxidative burst in TNF $\alpha$-primed neutrophils [37], and FC $\gamma \mathrm{R}$-dependent arachidonic acid release in dendritic cells in response to immune complexes [54].

Inhibition of Syk by R406 leads to inhibition of all downstream phosphorylation events of the Syk pathway, including PLC $\gamma 1, A k t / P K B, E r k, ~ p 38$ and JNK [37]. The specificity of fostamatinib/R406 for Syk is further supported by observations that the phenotype of R406-treated cells is similar to that observed after siRNA knockdown of syk in a basophilic cell line: siRNA knockdown of Syk mRNA and protein expression led to inhibition of Fc $\in$ R-induced signal transduction (i.e., phosphorylation of LAT, SLP-76, PLC $\gamma 1$ and Erk), degranulation and TNF- $\alpha$ release, all comparable to the inhibitory effects of R406 [55].

In platelets, Syk activation occurs through ITAM-containing GPVI (collagen receptor) and certain integrins ( $\alpha$ IIb $\beta 3$ ) [56-58]. As such, Braselmann et al. explored the effect of R406 inhibition in platelets from mice. In tail-tip bleeding assays of mice who were dosed orally with R406 (10, 30 and $100 \mathrm{mg} / \mathrm{kg}$ ), R406-treated mice did not 
show extended bleeding times compared with vehicle only $(57 \pm 16,59 \pm 12$, and $55 \pm 20$ s for R406 vs $78 \pm 29$ seconds for vehicle only); in contrast, aspirin treatment resulted in $88 \%$ prolongation in bleeding time to $147 \pm 51$ seconds [37]. Lack of detrimental effects on platelets was further confirmed in clinical studies of R406 in human subjects. In a double-blind, placebo-controlled, ascending-dose, randomized study, platelet-rich plasma was collected from R406-treated healthy male volunteers and assessed for collagen- or ADP-induced platelet aggregation [37]. No impairment in platelet aggregation was seen in the R406-treated platelets, consistent with prior studies showing little to no coagulation defect due to Syk-deficiency or GPVI deficiency in mice and human subjects, respectively [57,59].

In other in vivo studies, $\mathrm{R} 406$ abrogated dendritic cell priming of clonal $\mathrm{CD} 4^{+} \mathrm{T}$ cells following immune complex activation [60] and inhibited cellular interactions between immune complex-activated dendritic cells and antigenspecific $\mathrm{CD}^{+} \mathrm{T}$ cells, diminishing their development and proliferation in mice, while inhibiting production of proinflammatory cytokines IFN- $\gamma$ and IL-17 [60]. Development of thrombocytopenia and hemolytic anemia was also impeded by R406 in disease models of ITP and AIHA, respectively [38].

In animal models where antibodies against platelets and red cells were passively transferred to mice, fostamatinib treatment prevented the development of thrombocytopenia and hemolytic anemia, respectively [38]. In a disease model for ITP, mice injected with platelet-targeting anti-integrin $\alpha$-IIb antibodies develop profound thrombocytopenia within $24 \mathrm{~h}$. Mice pretreated with fostamatinib $(25$ or $40 \mathrm{mg} / \mathrm{kg}$ ) were significantly protected from developing thrombocytopenia, compared with no treatment or vehicle only, although slightly less than that seen with IVIg [38].

\section{Pharmacokinetics \& metabolism}

Fostamatinib is rapidly and completely hydrolyzed to R 406 in vitro with alkaline phosphatase and when incubated with human intestinal microsomes [31]. In rats, orally administered fostamatinib was highly bioavailable and showed rapid absorption with dose-proportional systemic exposure (following single fostamatinib dose, 10 or $20 \mathrm{mg} / \mathrm{kg}$ : AUC $_{0-16 \mathrm{~h}}=10,618 \mathrm{ng} \cdot \mathrm{h} / \mathrm{ml}$ and 30,650 ng $\cdot \mathrm{h} / \mathrm{ml}$, respectively; $C_{\max }=2600 \mathrm{ng} / \mathrm{ml}$ and $6500 \mathrm{ng} / \mathrm{ml}$, respectively; $\mathrm{t}_{1 / 2}=4.2 \mathrm{~h}$ ) [36]. Fostamatinib appeared to be completely converted to R406, as no prodrug was detected in plasma [36].

In healthy human subjects, R406 (dosed at 80-600 mg) was rapidly absorbed, with dose-proportional plasma concentrations at doses up to $400 \mathrm{mg}$ [46]. $\mathrm{C}_{\max }$ was reached by $1.3 \mathrm{~h}$ postdose, and $\mathrm{t}_{1 / 2}$ was approximately 15 h. In a multiple oral administration study of fostamatinib at $160 \mathrm{mg}$, R406 conversion occurred rapidly and extensively, with steady state achieved by 3-4 days after twice-daily administration, reaching an $\mathrm{AUC}_{\text {steady-state }}$ of $19,800 \pm 9350 \mathrm{ng} \cdot \mathrm{h} / \mathrm{ml}$ (mean exposure of $\sim 825 \mathrm{ng} / \mathrm{ml}$ ) and a $\mathrm{C}_{\max }$ of $1530 \mathrm{ng} / \mathrm{ml}$ [46]. These R406 concentrations are in range for robust inhibition of a blood pharmacodynamic biomarker shown previously in human volunteers using a Syk-dependent IgE-mediated basophil activation assay, where 50\% reduction of basophil activation was achieved with a R406 concentration of $496 \pm 42 \mathrm{ng} / \mathrm{ml}$ [37].

In a human mass balance study in six healthy adult males who were orally administered ${ }^{14} \mathrm{C}$-fostamatinib, $\mathrm{R} 406$ was the major drug compound detected in plasma, whereas only low levels of R 406 metabolites were found in circulation, suggesting rapid clearance of those metabolites [31]. Plasma half-life ranged from 10.8 to $15.7 \mathrm{~h}$. Overall mean recovery was $99.3 \%$, with $80 \%$ of drug recovery in the feces within $96 \mathrm{~h}$, and $19.3 \%$ via renal elimination within $72 \mathrm{~h}[31]$.

\section{Clinical studies \\ Efficacy}

In addition to Phase 1 PK studies in healthy subjects (described above), fostamatinib has been evaluated in a Phase II study of 16 patients, two phase three studies of 75 patients each (FIT1, FIT2), and an ongoing extension study of patients previously enrolled in FIT1 and FIT2 (Table 1) [38,61-63].

In a Phase II open-label, single center study, chronic ITP patients received escalating doses of oral fostamatinib, with initial doses of 75 to $150 \mathrm{mg}$ twice daily (b.i.d.), $12 \mathrm{~h}$ apart [38]. Patients were expected to complete at least 2 weeks of a given dose prior to dose increase in increments of $25 \mathrm{mg}$ twice daily to a maximum of $175 \mathrm{mg}$ twice daily. Response assessments were made weekly for the first 7 weeks of study, then every 1-4 weeks thereafter, depending on each patient's response status and clinical need. Responses were prospectively defined as an increase in platelet count by $>20,000 / \mu \mathrm{l}$ from baseline to at least 30,000/ $\mu \mathrm{l}$ without rescue treatment. Sustained responses were defined post-hoc as responses on at least $66 \%$ of study visits. 


\begin{tabular}{|c|c|c|c|c|c|c|c|}
\hline $\begin{array}{l}\text { Study/NCT } \\
\text { number }\end{array}$ & $\mathbf{N}$ & Study design & Fostamatinib dose & Primary end point & Key efficacy & Key safety & Ref. \\
\hline $\begin{array}{l}\text { Phase III } \\
\text { FIT1/NCT02076399 }\end{array}$ & 76 & $\begin{array}{l}\text { Multicenter, randomized, } \\
\text { double-blind, } \\
\text { placebo-controlled study } \\
\text { of FOSTA in treatment of } \\
\text { persistent/chronic ITP }\end{array}$ & $\begin{array}{l}100 \mathrm{mg} \text { po b.i.d.; dose } \\
\text { increase to } 150 \mathrm{mg} \text { b.i.d. } \\
\text { at week } \geq 4 \text { allowed }\end{array}$ & $\begin{array}{l}\text { Stable platelet response by } \\
\text { week } 24 \text { ( } \geq 50,000 / \mu \text { l on at } \\
\text { least four of six clinic visits } \\
\text { between weeks } 14-24)\end{array}$ & NA & NA & [63] \\
\hline $\begin{array}{l}\text { Phase III } \\
\text { FIT2/NCT02076412 }\end{array}$ & 74 & Parallel study to FIT1 & $\begin{array}{l}100 \mathrm{mg} \text { po b.i.d.; dose } \\
\text { increase to } 150 \mathrm{mg} \text { b.i.d. } \\
\text { at Week } \geq 4 \text { allowed }\end{array}$ & $\begin{array}{l}\text { Stable platelet response by } \\
\text { week } 24 \text { ( } \geq 50,000 / \mu \text { I on at } \\
\text { least four of six clinic visits } \\
\text { between weeks } 14-24)\end{array}$ & & & [62] \\
\hline $\begin{array}{l}\text { Extension study } \\
049 / \text { NCT02077192 }\end{array}$ & 124 & $\begin{array}{l}\text { Extension study to FIT1 } \\
\text { and FIT2 }\end{array}$ & 100 or 150 mg po b.i.d. & $\begin{array}{l}\text { Number of patients with } \\
\text { platelet count } \geq 50,000 / \mu l\end{array}$ & NA & NA & [61] \\
\hline
\end{tabular}

b.i.d.: Twice daily; Gl: Gastrointestinal; ITP: Immune thrombocytopenia; NA: Not available; po: Per oral route; TPO-RA: Thrombopoietin receptor agonist.

Sixteen adult patients were enrolled, six male and 10 female [38]. Median age was 66 years (range, 31-81), and $81 \%$ were white. Median duration of ITP was 9 years (range, 1-29+). Eight patients (50\%) had at least three comorbidities, and $15(94 \%)$ had a history of three or more prior treatments for ITP, including steroids (100\%), IVIg (94\%), rituximab (88\%), splenectomy (69\%), anti-D (56\%) and TPO agents (31\%). Median platelet count at baseline was $16,000 / \mu \mathrm{l}$ (range, 2000-28,000) [38].

Twelve patients $(75 \%)$ responded to fostamatinib, with median platelet count increasing from $16,000 / \mathrm{ml}$ to a median peak of $105,000 / \mathrm{ml}$ while on study drug; three responders were TPO-RA-refractory (Figure 6) [38]. Eight patients (50\%) showed sustained responses, reduced need for IVIg treatment, and tapering of steroids while on treatment. Four patients showed responses during $25 \%$ of study visits, with platelet counts increasing from a median $17,000 / \mu \mathrm{l}$ at baseline to $177,000 / \mu \mathrm{l}$ while on study drug. Four patients did not respond [38].

Two parallel Phase III, multicenter, randomized, double-blind, placebo-controlled studies of fostamatinib in treatment of persistent/chronic ITP have been completed [62,63]. Patients were randomized 2:1 to receive fostamatinib versus placebo b.i.d. (morning and evening) per oral route for 24 weeks. Unlike the Phase II study, the primary efficacy end point was achievement of a stable platelet response by week 24 (defined as $\geq 50,000 / \mu l$ on at least four of the six clinic visits occurring every other week between weeks 14 and 24). Other end points included safety and rates and severity of bleeding. Patients who successfully completed the scheduled 24-week treatment period or nonresponders who received fostamatinib $150 \mathrm{mg}$ or placebo b.i.d. for at least 4 weeks had the option to enroll in the long-term follow-up extension study (Study 049) [61]. The results of these studies have not yet been reported other than in abstract form. A manuscript is in preparation.

In addition to ITP, fostamatinib has shown activity in clinical studies of patients with rheumatoid arthritis, including those with inadequate responses to TNF- $\alpha$ antagonists or to methotrexate and other disease-modifying antirheumatic drugs [64-67]. In Phase III studies of fostamatinib in these patients, American College of Rheumatology 20\% (ACR20) responses were achieved in a significantly greater proportion of patients when they received fostamatinib $100 \mathrm{mg}$ b.i.d. for at least 24 weeks, compared with placebo [65,67]. Phase II studies in patients refractory to disease-modifying antirheumatic drugs also demonstrated significant improvements over placebo in measures of ACR20, ACR50, ACR70 and in disease activity scores $[64,66]$.

In B-cell lymphomas, fostamatinib activity was initially demonstrated in a Phase I/II trial, where objective response rates of $22,10,55$ and $11 \%$ were reported in patients with diffuse large B-cell lymphoma (DLBCL), follicular lymphoma, small lymphocytic leukemia/chronic lymphocytic leukemia, and mantle cell lymphoma, respectively [68]. However, patients in a follow-up Phase II study in DLBCL achieved an objective response rates of only 3\% [69]. 


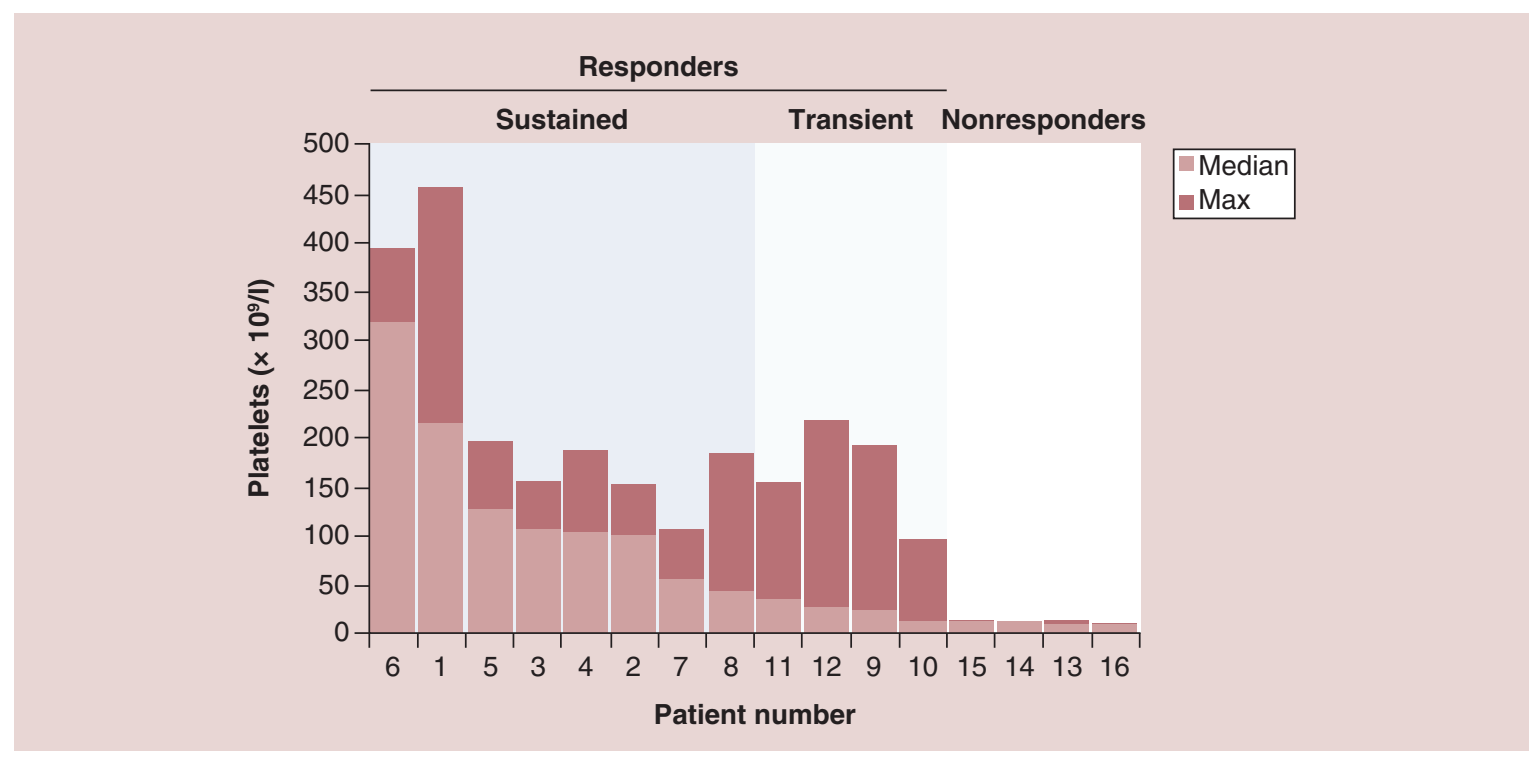

Figure 6. Platelet responses in immune thrombocytopenia patients receiving fostamatinib in Phase II, open-label, single-arm, cohort, dose-escalation study. Out of 16 cITP patients receiving oral fostamatinib, 12 patients responded, with mean platelet count $>100,000 / \mu \mathrm{l}$ : Eight achieved sustained responses exceeding $50,000 / \mu \mathrm{l}$ on more than $95 \%$ of study visits, and four had transient responses (during $25 \%$ of study visits). Four patients did not respond. Data were used from [38] to create this figure.

ITP: Immune thrombocytopenia.

Clinical efficacy and safety data from studies of fostamatinib in rheumatoid arthritis and B-cell lymphomas are summarized in Table 2.

\section{Safety \& tolerability}

In the Phase II study of fostamatinib in cITP, three patients withdrew because of toxicity (deep vein thrombosis, vomiting/diarrhea and worsening elevation of transaminase) [38] (Table 3). Most common AEs were gastrointestinalrelated reactions (diarrhea [38\%], nausea [25\%] and vomiting [19\%]). Most AEs were mild to moderate in severity, self-limited, and did not lead to treatment discontinuation. Liver function tests (ALT, AST, alkaline phosphatase) were mildly elevated in some patients, but managed with dose adjustments. Other common AEs included elevated systolic blood pressure $(n=5)$ and significant weight gain $(n=3)$; events of fatigue, drowsiness, headache, dizziness and shortness of breath appeared to be related to comorbidities in the study population and not related to study drug.

The safety and tolerability profile of fostamatinib in ITP appears to be consistent with that reported in clinical studies (e.g., rheumatoid arthritis, B-cell lymphomas), with increased but manageable rates of mostly low grade diarrhea, hypertension, and increases in liver function tests in patients receiving fostamatinib (Table 2) [60-67]. In a meta-analysis of five randomized clinical trials of fostamatinib in rheumatoid arthritis $(\mathrm{n}=1419$ receiving fostamatinib versus $n=686$ on placebo), fostamatinib increased the risk of infections ( 25 versus $14.7 \% ; p=0.001$ ), diarrhea ( 16.7 vs $5 \% ; p<0.00001)$; hypertension ( 17 vs $7.6 \% ; p=0.0003)$, and neutropenia ( 6.8 vs $0.8 \%$; $\mathrm{p}=0.001)$ [70]. Elevated blood pressure and rates of hypertension have been attributed to off-target effects of fostamatinib on VEGFR2, as described above. We speculate that the increased incidence of infections may be caused by the inhibition of phagocytosis, and thus the apparently tight therapeutic window may relate to the need to find the appropriate balance of phagocytic inhibition. Patients with rheumatoid arthritis on fostamatinib also trended toward having an increase in ALT $\geq 3 \mathrm{X}$ the upper limit of normal (4.2 vs $2.3 \% ; \mathrm{p}=0.05)$, but no drug-induced liver injury observed. Serious adverse events were rare.

In Phase I and II studies of fostamatinib in chronic lymphocytic leukemia/non-Hodgkin lymphoma and relapsed or refractory DLBCL, commonly reported treatment-related AEs were very similar to those reported above $[68,69]$. 
Table 2. Fostamatinib clinical trials in rheumatoid arthritis and B-cell lymphomas.

\begin{tabular}{|c|c|c|c|c|c|c|c|}
\hline $\begin{array}{l}\text { Study/NCT } \\
\text { number }\end{array}$ & $\mathbf{N}$ & Study design & Fostamatinib dose & Primary end point & Key efficacy & Key safety & Ref. \\
\hline \multicolumn{8}{|c|}{ Rheumatoid arthritis } \\
\hline $\begin{array}{l}\text { Phase III } \\
\text { NCT01197755 }\end{array}$ & 323 & $\begin{array}{l}\text { Randomized, } \\
\text { double-blind, } \\
\text { placebo-controlled in } \\
\text { patients with inadequate } \\
\text { response to tumor necrosis } \\
\text { factor-a antagonist }\end{array}$ & $\begin{array}{l}\text { A: Fostamatinib } 100 \mathrm{mg} \text { po } \\
\text { b.i.d. for } 24 \text { weeks } \\
(\mathrm{n}=105) \\
\text { B: Fostamatinib } 100 \mathrm{mg} \text { po } \\
\text { b.i.d. for } 4 \text { weeks, then } \\
150 \text { mg once daily } \\
(\mathrm{n}=108) \\
\text { C: Placebo po for } 24 \text { weeks } \\
(\mathrm{n}=110)\end{array}$ & ACR20 at Week 24 & $\begin{array}{l}\text { Significantly higher rates } \\
\text { of ACR } 20 \text { in Group } A \\
\text { versus placebo ( } 36.2 \text { vs } \\
21.1 \% ; p=0.004) . \text { Rates } \\
\text { of ACR } 20 \text { were } \\
\text { numerically higher in } \\
\text { Group } B \text {, but did not reach } \\
\text { significance versus placebo } \\
\text { ( } 27.8 \text { vs } 21.1 \% ; p=0.168 \text { ) }\end{array}$ & $\begin{array}{l}\text { Diarrhea }(20.0[\mathrm{~A}] \text { vs } 26.9 \\
\text { [B] vs } 6.4 \%[\mathrm{C}]) ; \\
\text { hypertension (13.3 vs } 13.9 \\
\text { vs } 8.3 \%) ; \text { headache ( } 7.6 \text { vs } \\
8.3 \% \text { vs } 10.1 \%) ; \text { elevated } \\
\text { bp } \geq 140 / 90 \mathrm{~mm} \mathrm{Hg} \mathrm{(46.7} \\
\text { vs } 51.9 \text { vs } 26.6 \%)\end{array}$ & [67] \\
\hline $\begin{array}{l}\text { Phase III } \\
\text { NCT1197521 }\end{array}$ & 918 & $\begin{array}{l}\text { Randomized, } \\
\text { double-blind, } \\
\text { placebo-controlled study } \\
\text { in patients receiving } \\
\text { methotrexate for RA }\end{array}$ & $\begin{array}{l}\text { A: Fostamatinib } 100 \mathrm{mg} \text { po } \\
\text { b.i.d. for } 52 \text { weeks } \\
\text { B: Fostamatinib } 100 \mathrm{mg} \text { po } \\
\text { b.i.d. for } 4 \text { weeks, then } \\
150 \mathrm{mg} \text { once daily } \\
\text { C: Placebo po for } 24 \\
\text { weeks, then fostamatinib } \\
100 \mathrm{mg} \text { b.i.d. }\end{array}$ & $\begin{array}{l}\text { (1) Change in } \\
\text { ACR20 from } \\
\text { baseline to } 24 \\
\text { weeks } \\
\text { (2) Change in } \\
\text { modified total } \\
\text { Sharp/van der } \\
\text { Heijde score of } \\
\text { radiographic } \\
\text { damage (SHS) }\end{array}$ & $\begin{array}{l}\text { Significantly higher rates } \\
\text { of ACR20 improvement in } \\
\text { Groups A or B versus } \\
\text { placebo ( } 49.0 \text { and } 44.4 \text {, } \\
\text { respectively, vs } 34.2 \% ; p \\
<0.01 \text {, both comparisons); } \\
\text { no difference in SHS } \\
\text { between treatment } \\
\text { groups }\end{array}$ & 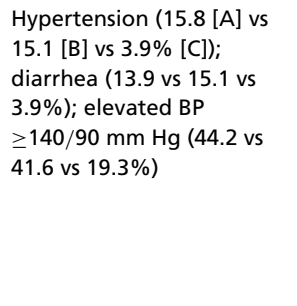 & [65] \\
\hline $\begin{array}{l}\text { Phase II } \\
\text { NCT00665925 }\end{array}$ & 457 & $\begin{array}{l}\text { Randomized, } \\
\text { double-blind, } \\
\text { placebo-controlled study } \\
\text { in patients with active RA } \\
\text { despite long-term } \\
\text { methotrexate therapy }\end{array}$ & $\begin{array}{l}\text { Fostamatinib } 100 \mathrm{mg} \text { or } \\
150 \mathrm{mg} \text { po b.i.d. vs } \\
\text { placebo }\end{array}$ & ACR20 at month 6 & $\begin{array}{l}\text { ACR20: } 67 \text { and } 57 \% \text { for } \\
\text { fostamatinib } 100 \text { and } \\
150 \text { mg b.i.d., respectively, } \\
\text { versus } 35 \% \text { for placebo ( } p \\
<0.001) \\
\text { ACR50: } 43 \text { and } 32 \text { versus } \\
19 \%(p<0.001 \text { and } 0.007 \text {, } \\
\text { respectively) } \\
\text { ACR70: } 28 \text { and } 14 \text { versus } \\
10 \%(p<0.001 \text { and } \\
p=0.34 \text {, respectively) }\end{array}$ & $\begin{array}{l}\text { Diarrhea (19 [fostamatinib } \\
100 \text { mg] vs } 3 \% \text { [placebo]); } \\
\text { upper respiratory } \\
\text { infections ( } 14 \text { vs } 7 \%) ; \\
\text { neutropenia ( } 6 \text { vs } 1 \%) ; \\
\text { initiation/change in } \\
\text { hypertension meds ( } 23 \text { vs } \\
7 \%)\end{array}$ & [64] \\
\hline $\begin{array}{l}\text { Phase Ilb } \\
\text { NCT0126477 }\end{array}$ & 279 & $\begin{array}{l}\text { Randomized, } \\
\text { placebo-controlled study } \\
\text { in RA patients not taking } \\
\text { DMARDs }\end{array}$ & $\begin{array}{l}\text { A: Fostamatinib } 100 \text { mg po } \\
\text { b.i.d. for } 24 \text { weeks } \\
\text { B: Fostamatinib } 100 \mathrm{mg} \text { po } \\
\text { b.i.d. for } 4 \text { weeks, then } \\
150 \text { mg q.d. to Week } 24^{\dagger} \\
\text { C: Fostamatinib } 100 \mathrm{mg} \text { po } \\
\text { b.i.d. for } 4 \text { weeks, then } \\
100 \text { g q.d. to Week } 24^{\dagger} \\
\text { D: Adalimumab } 40 \text { mg sc } \\
\text { every } 2 \text { weeks for } 24 \\
\text { weeks } \\
\text { E: Placebo po b.i.d. for } 6 \\
\text { weeks, then switch to Arm } \\
\text { A or } B^{\dagger}\end{array}$ & $\begin{array}{l}\text { Change in } \\
\text { DAS-28(CRP) from } \\
\text { baseline to Week } 6\end{array}$ & $\begin{array}{l}\text { Significant improvements } \\
\text { versus placebo in } \\
\text { DAS-28(CRP) scores } \\
\text { observed for Arms A and B } \\
(p=0.006 \text { and } 0022 \text {, } \\
\text { respectively), but not C, at } \\
6 \text { weeks; fostamatinib } \\
\text { arms inferior to } \\
\text { adalimumab at } 24 \text { weeks }\end{array}$ & $\begin{array}{l}\text { Diarrhea (16.7 [A] vs } \\
27.1 \%[\mathrm{~B}] \text { vs } 21.1 \%[\mathrm{C}] \text { vs } \\
1.9 \%[\mathrm{D}]) ; \text { hypertension } \\
(13.0 \text { vs } 6.3 \text { vs } 8.8 \text { vs } 9.3 \%)\end{array}$ & [66] \\
\hline \multicolumn{8}{|c|}{ B-cell lymphomas } \\
\hline $\begin{array}{l}\text { Phase I/II } \\
\text { NCT00446095 }\end{array}$ & $13 / 68$ & $\begin{array}{l}\text { Phase } 1 / 2 \text { study in patients } \\
\text { with recurrent } \mathrm{B} \text {-cell } \mathrm{NHL}\end{array}$ & $\begin{array}{l}\text { Fostamatinib } 200 \mathrm{mg} \text { po } \\
\text { bid, established during } \\
\text { dose-finding phase of } \\
\text { study }\end{array}$ & ORR & $\begin{array}{l}\text { ORR: } 22 \% \text { ( } 5 \text { of } 23 \text { ) for } \\
\text { patients with DLBCL; } 10 \% \\
(2 \text { of } 21 \text { ) for follicular } \\
\text { lymphoma, } 55 \% \text { ( } 6 \text { of } 11 \text { ) } \\
\text { for SLL/CLL; } 11 \% \text { ( } 1 \text { of } 9 \text { ) } \\
\text { for mantle cell lymphoma }\end{array}$ & $\begin{array}{l}\text { Diarrhea }(41 \%) \text {; fatigue } \\
(41 \%) ; \text { neutropenia }(31 \%) ; \\
\text { anemia }(27 \%) ; \\
\text { thrombocytopenia }(24 \%) ; \\
\text { hypertension }(24 \%) ; \\
\text { nausea }(21 \%)\end{array}$ & [68] \\
\hline $\begin{array}{l}\text { Phase II } \\
\text { NCT01499303 }\end{array}$ & 68 & $\begin{array}{l}\text { Randomized, } \\
\text { double-blinded study in } \\
\text { patients with relapsed or } \\
\text { refractory DLBCL }\end{array}$ & $\begin{array}{l}\text { Fostamatinib } 100 \mathrm{mg} \text { or } \\
200 \mathrm{mg} \text { po b.i.d. until } \\
\text { disease progression or } \\
\text { unacceptable toxicity }\end{array}$ & ORR & $\begin{array}{l}\text { ORR was } 3 \% \text { across both } \\
\text { arms, and the clinical } \\
\text { benefit rate was } 13 \%\end{array}$ & $\begin{array}{l}\text { Diarrhea }(21 \%) ; \text { nausea } \\
(19 \%) ; \text { fatigue }(18 \%)\end{array}$ & [69] \\
\hline \multicolumn{8}{|c|}{$\begin{array}{l}{ }^{\dagger} \text { Patients in the fostamatinib and placebo arms also received placebo injection every } 2 \text { weeks. } \\
{ }^{\ddagger} n=13 \text { in Phase } 1 ; n=68 \text { in Phase II } \\
\text { } \text { Due to limited efficacy in the initial } 35 \text { patients, the protocol was amended to treat all patients at the higher } 200 \text { mg b.i.d. dose; patients initially randomized to } 100 \text { mg b.i.d. also had } \\
\text { the opportunity to increase to the higher dose. } \\
\text { ACR20: American College of Rheumatology } 20 \% \text { response; bid: Twice daily; bp: Blood pressure; DAS-28(CRP): Disease activity score C-reactive protein; DLBCL: Diffuse large B-cell lymphoma; } \\
\text { DMARD: Disease-modifying antirheumatic drugs; NA: Not available; ORR: Objective response rate; po: Per oral route; q.d.: Once daily; SC: Subcutaneous; SLL/CLL: Small lymphocytic } \\
\text { leukemia/chronic lymphocytic leukemia. }\end{array}$} \\
\hline
\end{tabular}




\begin{tabular}{|c|c|}
\hline Adverse event, $\mathrm{n}(\%)$ & Fostamatinib $n=16$ \\
\hline Drowsiness/fatigue & $7(43.8)$ \\
\hline Diarrhea & $6(37.5)^{\dagger}$ \\
\hline Systolic blood pressure increased by $>10 \mathrm{mmHg}$ & $5(31.3)^{\dagger}$ \\
\hline Nausea & $4(25.0)^{\dagger}$ \\
\hline Headache & $4(25.0)^{\dagger}$ \\
\hline Weight gain $>5 \mathrm{~kg}$ & $3(18.8)^{\dagger}$ \\
\hline Vomiting & $3(18.8)^{\dagger}$ \\
\hline Abdominal pain & $3(18.8)^{\dagger}$ \\
\hline Shortness of breath & $3(18.8)$ \\
\hline Dizziness & $2(12.5)$ \\
\hline Constipation & $2(12.5)^{\dagger}$ \\
\hline Alanine aminotransferase $>2 \times$ upper limit of normal & $2(12.5)^{\dagger}$ \\
\hline Urinary tract infection & $1(6.3)$ \\
\hline Deep vein thrombosis & $1(6.3)$ \\
\hline Chest tightness & $1(6.3)$ \\
\hline Fever & $1(6.3)$ \\
\hline Blurry vision & $1(6.3)$ \\
\hline Lung hemangioma & $1(6.3)$ \\
\hline Lymphadenopathy & $1(6.3)$ \\
\hline
\end{tabular}

\section{Regulatory affairs}

Fostamatinib was granted Orphan Drug designation for treatment of patients with ITP in September 2015 [72]. A New Drug Application, submitted by Rigel Pharamceuticals, Inc, was accepted by the US FDA in June 2017 for fostamatinib in patients with persistent/chronic ITP [73,74]. Regulatory efforts with the European Medicines Authority and other regulatory agencies regarding marketing authorization for fostamatinib in ITP are in progress.

\section{Conclusion}

Persistent/chronic ITP is a heterogeneous disease that is associated with significant morbidity not limited to bleeding. Due to variability in its underlying pathobiology and natural history, management of disease can be unpredictable, as previously discussed. Furthermore, many patients experience unsustained responses regardless of treatment choice. Current guidelines for ITP are clearer for frontline treatment, but very uncertain for second line and beyond [75]. Thus, too great a proportion of patients have a significant unmet medical need because they cannot easily and safely manage their disease.

Syk inhibition represents a new approach to treatment of ITP, whereby macrophage destruction of platelets is inhibited at the site of phagocytosis. Fostamatinib has been explored in a number of diseases, primarily rheumatoid arthritis and now ITP. Final results from Phase III studies are pending but expected to be available shortly.

Collectively, both preclinical and clinical studies of fostamatinib demonstrate that fostamatinib is an active agent for treatment of ITP and represents a promising new therapy, including in heavily pretreated patients. Analysis of the two Phase III and extension studies will be very informative to the understanding of long-term efficacy and safety of fostamatinib in patients with ITP.

\section{Executive summary}

Overview of immune thrombocytopenia

- Primary immune thrombocytopenia (ITP) is an acquired autoimmune bleeding disorder characterized by autoantibody-mediated clearance of platelets and inhibition of megakaryocyte production of new platelets.

- Patients with ITP have platelet-reactive autoantibodies that arise from somatic mutations following perturbance of B- and T-cell tolerance mechanisms; these tolerance defects may occur centrally, peripherally or during differentiation. 
- ITP is associated with a skewed Th1/Th2 ratio that favors the survival of autoreactive T-cell and B-cell clones that produce anti-GPIIbIlla and Ib/IX antibodies.

- Antibody-coated platelets bind to antigen-presenting cells (i.e., macrophages and dendritic cells) via the FCR and are internalized and degraded via Syk-dependent cytoskeletal rearrangement.

Unmet medical need

- ITP is a heterogeneous disease that can persist for years despite the availability of several therapies with different mechanisms of action.

- Current guidelines recommend the use of corticosteroids (with or without IVIg and anti-D) as first-line therapy; for second- and later line therapy, options include use of surgical (i.e., splenectomy) or medical treatments (rituximab, TPO-RAs) which are often not curative and may have tolerability and/or toxicity issues.

- There is a need for additional therapeutic options for relapsed or refractory disease that target previously unexplored mechanisms of ITP pathogenesis.

Overview of fostamatinib disodium

- Fostamatinib disodium is an investigational agent in clinical development for the treatment of primary persistent/chronic adult ITP.

- It is a selective Syk inhibitor that protects platelets from destruction by inhibiting FcR-triggered cytoskeletal rearrangements needed for phagocytosis by macrophages.

- Fostamatinib has been studied in several preclinical models of autoimmune disease and in clinical studies of rheumatoid arthritis, lymphoma, nephropathy, autoimmune hemolytic anemia and ITP.

Spleen tyrosine kinase inhibition

- Syk is a cytoplasmic protein tyrosine kinase expressed extensively in hematopoietic cells, including macrophages, $B$ cells, T cells and platelets.

- It is recruited and activated when FCR binds to their ligands and subsequent phosphorylation of Immunoreceptor tyrosine-based activation motif.

- Syk activation induces downstream signaling cascades that results in cytoskeletal rearrangement and phagocytosis; Syk knockout mice produce phagocytosis-defective macrophages that appear to be dependent on FCR.

- Syk inhibition is protective against development of thrombocytopenia and anemia in murine models of ITP and autoimmune hemolytic anemia, respectively, and against inflammation in models of rheumatoid arthritis.

Preclinical studies of fostamatinib in ITP

- Fostamatinib is a highly bioavailable prodrug that is metabolized to the active metabolite, R406, in the presence of alkaline phosphatase or human intestinal microsomes.

- R406 shows selective and potent inhibition of Syk in in vitro and cell-based assays; it binds the catalytic domain of Syk $(\mathrm{Ki}=30 \mathrm{nM})$ and acts as an ATP-competitive inhibitor $\left(\mathrm{IC}_{50}=41 \mathrm{nM}\right)$.

- Fostamatinib/R406 inhibited or delayed progression or onset of several animal models of autoimmune and inflammatory diseases.

- Fostamatinib has a half-life ranging from $\sim 11$ to $16 \mathrm{~h}$, shows rapid absorption, and has dose-proportional systemic exposure, with the majority of drug elimination via the fecal route.

\section{Clinical studies of fostamatinib in ITP}

- Fostamatinib has been evaluated in one Phase II study $(n=16)$ and two Phase III studies $(n=75$ each) in patients with persistent/chronic ITP, and an ongoing extension studies of 124 patients previously enrolled in the Phase III studies.

- Findings of the Phase II study showed that $50 \%$ of patients had sustained responses $(>20,000 / \mu$ increase in platelets from baseline to $\geq 30,000 / \mu$ for $>67 \%$ of visits) to fostamatinib, and another $25 \%$ with transient responses, despite multiple prior therapies, including TPO-RA-refractory disease; responders showed an increase in median platelet counts from $16,000 / \mathrm{ml}$ to $105,000 / \mathrm{ml}$ while on study drug, reduced their need for IVIg treatment, and tapered steroid use while on treatment.

- The safety profile of fostamatinib in a Phase II study in ITP is consistent with fostamatinib in other indications, with most common AEs including gastrointestinal-related reactions (diarrhea, nausea and vomiting) and elevated blood pressure; most AEs have been mild to moderate, self-limited, and did not lead to treatment discontinuation.

- Compared with placebo, liver function tests (ALT, AST and alkaline phosphatase) and hypertension events were mildly elevated in some patients, but managed with dose reductions or medication.

\section{Conclusion}

- Preclinical and clinical studies have shown fostamatinib as a promising new approach to ITP that may be effective in heavily pretreated patients.

- Analysis of the Phase III and extension studies will provide a more grounded and comprehensive understanding of the efficacy and safety profile of fostamatinib in ITP. 
Financial \& competing interests disclosure

A Newland has received research support from Amgen, GSK and Novartis; he has participated on advisory boards for Amgen, Argenx, Dova Pharmaceuticals, and Novartis, and speakers bureaus for Amgen and Novartis. E Lee has received research support from Rigel Pharmaceuticals, Inc. V McDonald has received research support from Baxter and advisory fees for Alexion and J B Bussel has received research support from Novartis, Amgen, and Rigel Pharmaceuticals, Inc. and has participated on advisory boards for Novartis, Amgen, Momenta, Protalex, and Rigel Pharmaceuticals, Inc. The authors have no other relevant affiliations or financial involvement with any organization or entity with a financial interest in or financial conflict with the subject matter or materials discussed in the manuscript apart from those disclosed.

I Koo, a medical writer supported by funding from Rigel Pharmaceuticals, Inc., provided drafts and editorial assistance to the authors during preparation of this manuscript.

\section{References}

Papers of special note have been highlighted as: $\bullet$ of interest; $\bullet \bullet$ of considerable interest.

1. Rodeghiero F, Stasi R, Gernsheimer T et al. Standardization of terminology, definitions and outcome criteria in immune thrombocytopenic purpura of adults and children: report from an international working group. Blood 113(11), 2386-2393 (2009).

2. Zufferey A, Kapur R, Semple J. Pathogenesis and therapeutic mechanisms in immune thrombocytopenia (ITP). J. Clin. Med. 6(2), 1-21 (2017).

3. Cohen YC, Djulbegovic B, Shamai-Lubovitz O, Mozes B. The bleeding risk and natural history of idiopathic thrombocytopenic purpura in patients with persistent low platelet counts. Arch. Intern. Med. 160(11), 1630-1638 (2000).

4. Kistangari G, McCrae KR. Immune thrombocytopenia. Hematol. Oncol. Clin. North Am. 27(3), 497-520 (2013).

5. Terrell DR, Beebe LA, Vesely SK, Neas BR, Segal JB, George JN. The incidence of immune thrombocytopenic purpura in children and adults: A critical review of published reports. Am. J. Hematol. 85(3), 174-180 (2010).

6. Fogarty PF, Segal JB. The epidemiology of immune thrombocytopenic purpura. Curr. Opin. Hematol. 14(5), 515-519 (2007).

7. Provan D, Stasi R, Newland AC et al. International consensus report on the investigation and management of primary immune thrombocytopenia. Blood 115(2), 168-187 (2010).

- Frequently referenced international guidelines for the diagnosis and management of primary immune thrombocytopenia (ITP), developed to aid clinicians in decision-making.

8. Crowley MT, Costello PS, Fitzer-Attas CJ et al. A critical role for Syk in signal transduction and phagocytosis mediated by Fc $\gamma$ receptors on macrophages. J. Exp. Med. 186(7), 1027-1039 (1997).

- Landmark study demonstrating the role of Syk-mediated signal transduction in cytoskeletal rearrangements required for phagocytosis by macrophages. Findings from this study are the basis for the proposed mechanism of action of fostamatinib/R406.

9. Nugent D, McMillan R, Nichol JL, Slichter SJ. Pathogenesis of chronic immune thrombocytopenia: increased platelet destruction and/or decreased platelet production. Br. J. Haematol. 146(6), 585-596 (2009).

10. George JN, Aster RH. Drug-induced thrombocytopenia: pathogenesis, evaluation, and management. Hematol. Am. Soc. Hematol. Educ. Progr. 2009, 153-158 (2009).

11. Cines DB, Bussel JB, Liebman HA et al. The ITP syndrome: pathogenic and clinical diversity review article the ITP syndrome: pathogenic and clinical diversity. Blood 113(26), 6511-6521 (2009).

- Study describing the differences between primary and secondary ITP and how the underlying etiology nay be more deep-rooted in the ones with greater underlying abnormalities of immune function.

12. Sakakura M, Wada H, Tawara I et al. Reduced Cd4+Cd25+ T cells in patients with idiopathic thrombocytopenic purpura. Thromb. Res. 120(2), 187-193 (2007).

13. Zhang J, Ma D, Zhu X, Qu X, Ji C, Hou M. Elevated profile of Th17, Th1 and Tc1 cells in patients with immune thrombocytopenic purpura. Haematologica 94(9), 1326-1329 (2009).

14. Hu Y, Ma D, Shan N et al. Increased number of Tc17 and correlation with Th17 cells in patients with immune thrombocytopenia. PLoS ONE 6(10), e26522 (2011).

15. Toltl LJ, Nazi I, Jafari R, Arnold DM. Piecing together the humoral and cellular mechanisms of immune thrombocytopenia. Semin. Thromb. Hemost. 37(6), 631-639 (2011).

16. Olsson B, Andersson P-O, Jernas M et al. T-cell-mediated cytotoxicity toward platelets in chronic idiopathic thrombocytopenic purpura. Nat. Med. 9(9), 1123-1124 (2003).

17. McMillan R, Wang L, Tani P. Prospective evaluation of the immunobead assay for the diagnosis of adult chronic immune thrombocytopenic purpura (ITP). J. Thromb. Haemost. 1(3), 485-491 (2003).

18. McMillan R. Antiplatelet antibodies in chronic immune thrombocytopenia and their role in platelet destruction and defective platelet production. Hematol. Oncol. Clin. North Am. 23(6), 1163-1175 (2009). 
19. Cines DB, Blanchette versus Immune thrombocytopenic purpura. N. Engl. J. Med. 346(13), 995-1008 (2002).

20. Stasi R. Immune thrombocytopenia: pathophysiologic and clinical update. Semin. Thromb. Hemost. 38(5), 454-462 (2012).

21. Houwerzijl EJ, Blom NR, van der Want JJL et al. Ultrastructural study shows morphologic features of apoptosis and para-apoptosis in megakaryocytes from patients with idiopathic thrombocytopenic purpura. Blood 103(2), 500-506 (2004).

22. Chang M, Nakagawa PA, Williams SA et al. Immune thrombocytopenic purpura (ITP) plasma and purified ITP monoclonal autoantibodies inhibit megakaryocytopoiesis in vitro. Blood 102(3), 887-895 (2003).

23. McMillan R, Wang L, Tomer A, Nichol J, Pistillo J. Suppression of in vitro megakaryocyte production by antiplatelet autoantibodies from adult patients with chronic ITP. Blood 103(4), 1364-1369 (2004).

24. McMillan R. Antiplatelet antibodies in chronic adult immune thrombocytopenic purpura: assays and epitopes. J. Pediatr. Hematol. Oncol. 25(Suppl. 1), S57-S61 (2003).

25. Nørgaard M, Cetin K, Maegbaek ML et al. Risk of arterial thrombotic and venous thromboembolic events in patients with primary chronic immune thrombocytopenia: a Scandinavian population-based cohort study. Br. J. Haematol. 174, 637-651 (2016).

26. McMillan R, Bussel JB, George JN, Lalla D, Nichol JL. Self-reported health-related quality of life in adults with chronic immune thrombocytopenic purpura. Am. J. Hematol. 83, 150-154 (2008).

27. Snyder CF, Mathias SD, Cella D, Isitt JJ, Wu AW, Young J. Health-related quality of life of immune thrombocytopenic purpura patients: results from a web-based survey. Curr. Med. Res. Opin. 24(10), 2767-2776 (2008).

28. Doobaree IU, Nandigam R, Bennett D, Newland A, Provan D. Thromboembolism in adults with primary immune thrombocytopenia: a systematic literature review and meta-analysis. Eur. J. Haematol. 97(4), 321-330 (2016).

29. Sarpatwari A, Bennett D, Logie JW et al. Thromboembolic events among adult patients with primary immune thrombocytopenia in the United Kingdom general practice research database. Haematologica 95(7), 1167-1175 (2010).

30. Sarpatwari A, Watson S, Erqou $S$ et al. Health-related lifestyle in adults and children with primary immune thrombocytopenia (ITP). Br. J. Haematol. 151(2), 189-191 (2010).

31. Sweeny DJ, Li W, Clough J et al. Metabolism of fostamatinib, the oral methylene phosphate prodrug of the spleen tyrosine kinase inhibitor R406 in humans: Contribution of hepatic and gut bacterial processes to the overall biotransformation. Drug Metab. Dispos. 38(7), 1166-1176 (2010).

32. Salama A. Emerging drugs for immune thrombocytopenia (ITP). Expert Opin. Emerg. Drugs 22(1), 27-38 (2017).

33. Neunert C, Lim W, Crowther M. The American Society of Hematology 2011 evidence-based practice guideline for immune thrombocytopenia. Blood 117(16), 4190-4207 (2011).

- ASH guidelines for the diagnosis and management of ITP, developed with an evidence-based approach using from the GRADE system, which categorizes evidence based on the quality and strength of of contributing evidence.

34. McAdoo SP, Tam FWK. Fostamatinib disodium. Drug Data Rep. 31(2), 173 (2009).

35. Weinblatt ME, Kavanaugh A, Burgos-Vargas R et al. Treatment of rheumatoid arthritis with a Syk kinase inhibitor: a twelve-week, randomized, placebo-controlled trial. Arthritis Rheum. 58(11), 3309-3318 (2008).

36. Pine PR, Chang B, Schoettler $\mathrm{N}$ et al. Inflammation and bone erosion are suppressed in models of rheumatoid arthritis following treatment with a novel Syk inhibitor. Clin. Immunol. 124(3), 244-257 (2007).

37. Braselmann S, Taylor V, Zhao H et al. R406, an orally available spleen tyrosine kinase inhibitor blocks fc receptor signaling and reduces immune complex-mediated inflammation. J. Pharmacol. Exp. Ther. 319(3), 998-1008 (2006).

-. First-in-human study demonstrating oral bioavailability of R406 and potential for modulating spleen tyrosine kinase activity in human disease. Mechanism of action of R406 is established, with R406 binding to the ATP binding pocket of spleen tyrosine kinase and competitively inhibiting its kinase activity.

38. Podolanczuk A, Lazarus AH, Crow AR, Grossbard E, Bussel JB. Of mice and men: an open-label pilot study for treatment of immune thrombocytopenic purpura by an inhibitor of Syk. Blood 113(14), 3154-3160 (2009).

-. Initial proof-of-concept, open-label, single-arm cohort dose-escalation trial demonstrating a $50 \%$ sustained response rate from patients receiving fostamatinib, with manageable side effects. Also demonstrated was the activity of fostamatinib in mouse models of ITP and autoimmune hemolytic anemia.

39. Mócsai A, Ruland J, Tybulewicz VLJ. The SYK tyrosine kinase: a crucial player in diverse biological functions. Nat. Rev. Immunol. 10(6), 387-402 (2010).

40. Takada Y, Aggarwal BB. TNF activates Syk protein tyrosine kinase leading to TNF-induced MAPK activation, NF-kappaB activation, and apoptosis. J. Immunol. 173(2), 1066-1077 (2004).

41. Hilgendorf I, Eisele S, Remer I et al. The oral spleen tyrosine kinase inhibitor fostamatinib attenuates inflammation and atherogenesis in low-density lipoprotein receptor-deficient mice. Arterioscler. Thromb. Vasc. Biol. 31(9), 1991-1999 (2011).

42. Colonna L, Catalano G, Chew C et al. Therapeutic targeting of Syk in autoimmune diabetes. J. Immunol. 185(3), 1532-1543 (2010).

43. Deng G-M, Liu L, Bahjat FR, Pine PR, Tsokos GC. Suppression of skin and kidney disease by inhibition of spleen tyrosine kinase in lupus-prone mice. Arthritis Rheum. 62(7), 2086-2092 (2010). 
44. Bahjat FR, Pine PR, Reitsma A et al. An orally bioavailable spleen tyrosine kinase inhibitor delays disease progression and prolongs survival in murine lupus. Arthritis Rheum. 58(5), 1433-1444 (2008).

45. Matsubara S, Koya T, Takeda $\mathrm{K}$ et al. Syk activation in dendritic cells is essential for airway hyperresponsiveness and inflammation. Am. J. Respir. Cell Mol. Biol. 34(4), 426-433 (2006).

46. Baluom M, Grossbard EB, Mant T, Lau DTW. Pharmacokinetics of fostamatinib, a spleen tyrosine kinase (SYK) inhibitor, in healthy human subjects following single and multiple oral dosing in three Phase I studies. Br. J. Clin. Pharmacol. 76(1), 78-88 (2013).

47. Davis MI, Hunt JP, Herrgard S et al. Comprehensive analysis of kinase inhibitor selectivity. Nat. Biotechnol. 29(11), 1046-1051 (2011).

48. Rolf MG, Curwen JO, Veldman-Jones $\mathrm{M}$ et al. In vitro pharmacological profiling of R406 identifies molecular targets underlying the clinical effects of fostamatinib. Pharma Res. Per. 3(3), 5-175 (2015).

49. Cha H-S, Boyle DL, Inoue T et al. A novel spleen tyrosine kinase inhibitor blocks c-Jun N-terminal kinase-mediated gene expression in synoviocytes. J. Pharmacol. Exp. Ther. 317(2), 571-578 (2006).

50. Skinner M, Philp K, Lengel D et al. The contribution of VEGF signalling to fostamatinib-induced blood pressure elevation. Br. J. Pharmacol. 171(9), 2308-2320 (2014).

51. Lengel D, Bergstrom EL, Barthlow $\mathrm{H}$ et al. Prevention of fostamatinib-induced blood pressure elevation by antihypertensive agents. Pharmacol Res Perspect. 3(5), e00176 (2015).

52. Young RM, Hardy IR, Clarke RL et al. Mouse models of non-Hodgkin lymphoma reveal Syk as an important therapeutic target. Blood 113(11), 2508-2516 (2009).

53. Suljagic M, Longo PG, Bennardo $S$ et al. The Syk inhibitor fostamatinib disodium (R788) inhibits tumor growth in the Emu- TCL1 transgenic mouse model of CLL by blocking antigen-dependent B-cell receptor signaling. Blood 116(23), 4894-4905 (2010).

54. Valera I, Fernandez N, Trinidad AG et al. Costimulation of dectin-1 and DC-SIGN triggers the arachidonic acid cascade in human monocyte-derived dendritic cells. J. Immunol. 180(8), 5727-5736 (2008).

55. Sanderson MP, Gelling SJ, Rippmann JF, Schnapp A. Comparison of the anti-allergic activity of Syk inhibitors with optimized Syk siRNAs in FcepsilonRI-activated RBL-2H3 basophilic cells. Cell. Immunol. 262(1), 28-34 (2010).

56. Poole A, Gibbins JM, Turner $\mathrm{M}$ et al. The Fc receptor gamma-chain and the tyrosine kinase Syk are essential for activation of mouse platelets by collagen. EMBO J. 16(9), 2333-2341 (1997).

57. Law DA, Nannizzi-Alaimo L, Ministri K et al. Genetic and pharmacological analyses of Syk function in alphaIIb beta3 signaling in platelets. Blood 93(8), 2645-2652 (2017).

58. Clark E a, Shattil SJ, Ginsberg MH, Bolen J, Brugge JS. Regulation of the protein tyrosine kinase pp72syk by platelet agonists and the integrin alpha IIb beta 3. J. Biol. Chem. 269(46), 28859-28864 (1994).

59. Moroi M, Shinmyozut K, Hospital KC. A patient with platelets deficient. 84, 1440-1445 (1989).

60. Platt AM, Benson RA, McQueenie R et al. The active metabolite of spleen tyrosine kinase inhibitor fostamatinib abrogates the CD4??? $\mathrm{T}$ cell-priming capacity of dendritic cells. Rheumatology (Oxford). 54(1), 169-177 (2015).

61. Clinical trials database: NCT02077192. www.clinicaltrials.gov/ct2/show/NCT02077192.

62. Clinical trials database: NCT02076412. www.clinicaltrials.gov/ct2/show/NCT02076412.

63. Clinical trials database: NCT02076399. www.clinicaltrials.gov/ct2/show/NCT02076399.

64. Weinblatt ME, Kavanaugh A, Genovese MC, Musser TK, Grossbard EB, Magilavy DB. An oral spleen tyrosine kinase (Syk) inhibitor for rheumatoid arthritis. N. Engl. J. Med. 363(14), 1303-1312 (2010).

65. Weinblatt ME, Genovese MC, Ho M et al. Effects of fostamatinib, an oral spleen tyrosine kinase inhibitor, in rheumatoid arthritis patients with an inadequate response to methotrexate: results from a Phase III, multicenter, randomized, double-blind, placebo-controlled, parallel-group study. Arthritis Rheumatol. 66(12), 3255-3264 (2014).

66. Taylor PC, Genovese MC, Greenwood M et al. OSKIRA-4: a Phase IIb randomised, placebo-controlled study of the efficacy and safety of fostamatinib monotherapy. Ann. Rheum. Dis. 74(12), 2123-2129 (2015).

67. Genovese MC, van der Heijde DM, Keystone EC et al. A Phase III, multicenter, randomized, double-blind, placebo-controlled, parallel-group study of 2 dosing regimens of fostamatinib in patients with rheumatoid arthritis with an inadequate response to a tumor necrosis factor-alpha antagonist. J. Rheumatol. 41(11), 2120-2128 (2014).

68. Friedberg JW, Sharman J, Sweetenham J et al. Inhibition of Syk with fostamatinib disodium has significant clinical activity in non-Hodgkin lymphoma and chronic lymphocytic leukemia. Blood 115(13), 2578-2585 (2010).

69. Flinn IW, Bartlett NL, Blum KA et al. A Phase II trial to evaluate the efficacy of fostamatinib in patients with relapsed or refractory diffuse large B-cell lymphoma (DLBCL). Eur. J. Cancer 54, 11-17 (2016).

70. Kunwar S, Devkota AR, Ghimire DKC. Fostamatinib, an oral spleen tyrosine kinase inhibitor, in the treatment of rheumatoid arthritis: a meta-analysis of randomized controlled trials. Rheumatol. Int. 36(8), 1077-1087 (2016). 
71. Kitas G, Abreu G, Jedrychowicz-Rosiak K et al. The effects of the spleen tyrosine kinase inhibitor fostamatinib on ambulatory blood pressure in patients with active rheumatoid arthritis: results of the OSKIRA-ABPM (ambulatory blood pressure monitoring) randomized trial. J. Am. Soc. Hypertens. 8(11), 780-790 (2014).

72. Rigel Pharmaceuticals Inc. Rigel granted orphan drug designation for fostamatinib in ITP. Press Release. (2015). www.prnewswire.com/news-releases/rigel-granted-orphan-drug-designation-for-fostamatinib-in-itp-300138809.html

73. Rigel Pharmaceuticals Inc. Rigel submits new drug application to FDA for fostamatinib in chronic ITP. Press Release. (2017) www.prnewswire.com/news-releases/rigel-submits-new-drug-application-to-fda-for-fostamatinib-in-chronic-itp-300440366.html

74. Rigel Pharmaceuticals Inc. FDA accepts rigel's new drug application for TAVALISSE ${ }^{\text {TM }}$ (fostamatinib disodium) for the treatment of chronic ITP. Press Release. (2017). www.prnewswire.com/news-releases/fda-accepts-rigels-new-drug-application-for-tavalissefostamatinib-disodium-for-the-treatment-of-chronic-itp-300475653.html

75. Ghanima W, Godeau B, Cines DB, Bussel JB. How I treat immune thrombocytopenia: the choice between splenectomy or a medical therapy as a second-line treatment. Blood 120(5), 960-969 (2012). 
